\title{
A tribute to Arno Motulsky
}

D r. Arno Motulsky, one of the founders of medical genetics, died on January 17, 2018, at his home in Seattle. He was 94 years old. Arno was a professor emeritus at the University of Washington School of Medicine and a member of the National Academy of Sciences and the National Academy of Medicine.

Motulsky was born and raised in the then-German town of Fischhausen on the Baltic Sea, but with the rise of Nazism, his family realized that they had to leave Germany. His father left for Cuba, waiting for a visa to enter the United States, and, in 1939, Arno, his mother, and two siblings left Hamburg for Cuba on a ship named the St. Louis. Famously, the almost one thousand Jewish refugees on board were denied entry into any port of the Caribbean or the US, and the ship had to return to Europe. Motulsky and his family were allowed entry into Belgium, but when the Germans invaded that country in 1940, Arno, then 17 years old, ended up in an internment camp in France. In 1941, he successfully escaped, crossed Spain into Portugal, sailed to America, and joined his father in Chicago.

In 1943, Arno joined the US army and, having been accepted to the University of Illinois Medical School, was assigned by the army to a specialized program for rapid training of young physicians. He was released from the army in 1946, finished medical school in 1947, and began a residency in internal medicine. He followed this with a fellowship in hematology at the Michael Reese Hospital in Chicago in the laboratory of Carl Singer, where his research focused on the molecular characterization of the hemoglobin of sickle cell patients using an immunological approach. These experiments were conducted before the electrophoretic demonstration of hemoglobin S by Linus Pauling that established the concept of molecular disease. Sickle cell anemia and the hemoglobinopathies remained one of Arno's interests for the rest of his life. When the Korean War erupted in 1951,
Arno went back into the army and was assigned to work at Walter Reed Hospital in Washington, D.C., where he joined the hematology unit of William Crosby to study hemolytic anemias.

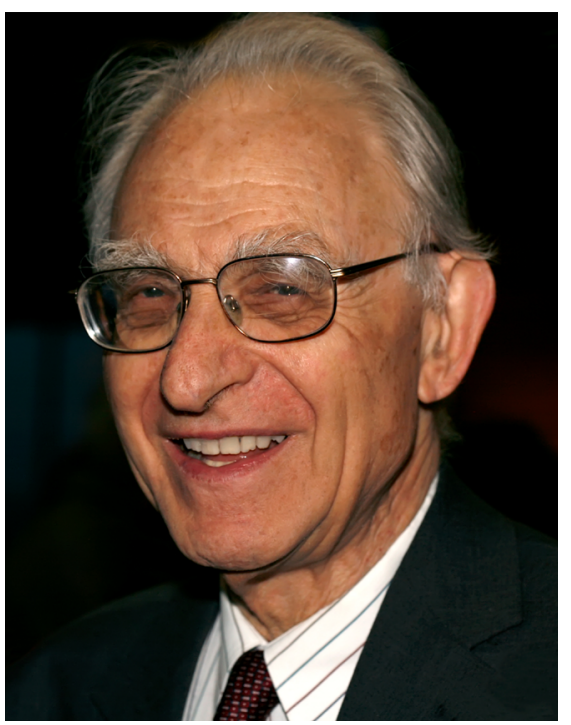

In 1953, Arno was recruited by the late Clement Finch to join the newly formed Division of Hematology at the University of Washington in Seattle, and he started his university career with a research focus on the hemoglobinopathies and other inherited red cell disorders. One of his early contributions was the demonstration that a red cell defect in the mouse, hereditary spherocytosis, could be cured by bone marrow transplantation (1). He also demonstrated that the degree of hemolysis in murine spherocytosis can be modulated by heating, providing an early example of environment-gene interactions in a mammalian model (2).

He started teaching genetics to medical students using the hemoglobinopathies as a model, and in 1956, the late Robert Williams, founder of the Department of Medicine at the University of Washington, realizing Arno's tremendous potential as well as the importance of genetics for the future of medicine, asked Arno to establish a division of medical genetics. Arno accepted under the condition that before he established the division he would spend some time increasing his expertise in human and mathematical genetics. To this end, he spent a year at the Galton Laboratory in London, at that time the premier institution in human and mathematical genetics, where he studied under prominent geneticists Lionel Penrose and J.B.S. Haldane. When he returned to Seattle in 1957, Arno founded the Division of Medical Genetics at the University of Washington. Arno's Division and that of Victor McKusick at Johns Hopkins, also established in 1957, were the first medical genetics divisions in the US. In 1957, Arno initiated the medical genetics clinic that, for the next half century, was the epicenter of his teaching activities.

One of Arno's early interests was in the interaction between genes and drugs, for which he coined the term "pharmacogenetics" (3). He was fascinated by the condition known as primaquine sensitivity, the hemolytic anemia appearing in G6PD-deficient African American males who are exposed to antimalarial drugs. He devised a very simple but highly accurate dye decoloration test for the diagnosis of G6PD deficiency (4), which is still being used extensively as a diagnostic tool around the world. This test is known in several Mediterranean countries as the "Motulsky test." By its simplicity and accuracy, the Motulsky test allowed the study of large population samples to determine the frequency and geographic distribution of G6PD deficiency, and it has been used in hundreds of population pharmacogenetic studies around the world. In the early 1960s, the selective forces that shaped the high frequencies of G6PD deficiency in certain populations were unknown. Arno hypothesized that malarial selection was the cause and tested the hypothesis with population studies correlating the frequencies of G6PD deficiency to the severity of malarial endemicity. Arno's initial studies in Africa (5) and Sardinia (6) and subsequent studies in several other populations provided evidence in support of the malaria hypothesis. 
Arno started his postdoctoral medical genetics training program in the early 1960s, and during the 1960s, he trained several medical geneticists who subsequently became leaders in the field. The early 1970s were special for Arno's program, when a group of stellar postdoctoral fellows from the US and Europe came for training in Seattle. One of these was Joseph Goldstein, fresh from a research fellowship in Marshall Nirenberg's laboratory at the NIH. It was characteristic of Arno's approach to mentoring that he did not direct Goldstein toward lab bench research, as one would have expected on the basis of Joe's research background, but instead toward the much broader question of the genetics of coronary artery disease and the role of hyperlipidemia in that disease. Until that time, the genetics of hyperlipidemias were quite confusing and mostly based on interpretations of plasma lipid fractionations. Goldstein and Motulsky organized an epidemiological study and clinical investigation involving 11 Seattle hospitals to determine the frequency of lipid disorders in unselected myocardial infarction survivors and their families that resulted in a landmark achievement: the clear-cut recognition and genetic characterization of three monogenically determined hyperlipidemias $(7,8)$. A few years later, Goldstein and Brown, working at UT Southwestern, shared the Nobel Prize in Physiology or Medicine for their discovery of the LDL receptor and the delineation of the molecular defect of familial hypercholesterolemia. Arno continued his research on the genetics of common, complex disorders throughout his career.
Arno had had a very large impact on the development of the field of medical genetics in this country and around the world through his mentoring and training of medical geneticists. As a research mentor, he stimulated his trainees to address broad and complicated questions. His way of mentoring became a model for the field (9). Together with the late Friedrich Vogel, he authored the standard textbook of the field, Human Genetics: Problems and Approaches, which is now in its fourth edition and has been translated into several languages.

Arno was a great intellectual and a great friend. I started collaborating with him in 1962 on population studies testing the malarial resistance/selection hypothesis in G6PD and thalassemia, and in 1964 he recruited me to Seattle, where our collaboration continued for several years. As a collaborator, Arno was demanding and challenging but always inspiring. $\mathrm{He}$ was also a Renaissance man who always enjoyed intellectual discussions, particularly on history, philosophy, and ethics.

Arno has received many distinctions. He was a member of the American Society for Clinical Investigation, the Association of American Physicians, and the American Philosophical Society. The American Society of Human Genetics honored him with all three of its major awards: the William Allen Memorial Award, the Excellence in Education Award, and the Victor A. McKusick Leadership Award, and it established in his honor the Arno Motulsky-Barton Childs Award for Excellence in Human Genetics Education.

\section{George Stamatoyannopoulos}

Departments of Medicine and Genome Sciences, University of Washington, Seattle, Washington, USA. Email: gstam@uw.edu.

1. Motulsky AG, Anderson R, Sparkes RS, Huestis $\mathrm{RH}$. Marrow transplantation in newborn mice with hereditary spherocytosis: a model system. Trans Assoc Am Physicians. 1962;75:64-72.

2. Anderson R, Motulsky AG. Adverse effects of raised environment temperature on the expression of hereditary spherocytosis in deer mice. Blood. 1966;28(3):365-376.

3. Motulsky AG. Pharmacogenetics. Prog Med Genet. 1964;23:49-74.

4. Motulsky AG, Campbell-Kraut JM. Population genetic of glucose-6-phosphate dehydrogenase deficiency of the red cell. In: Blumberg BS, ed. Proceedings of the Conference on Genetic Polymorphisms and Geographic Variations in Disease. New York, New York, USA: Grune \& Stratton; 1960:159-181.

5. Motulsky AG, Vandepitte J, Fraser GR. Population genetic studies in the Congo. I. Glucose6-phosphate dehydrogenase deficiency, hemoglobin S, and malaria. Am JHum Genet. 1966;18(6):514-537.

6. Siniscalco M, Bernini L, Latte B, Motulsky AG. Favism and thalassaemia in Sardinia and their relationship to malaria. Nature. 1961;190:1179-1180.

7. Goldstein JL, Hazzard WR, Schrott HG, Bierman EL, Motulsky AG. Hyperlipidemia in coronary heart disease. I. Lipid levels in 500 survivors of myocardial infarction. J Clin Invest. 1973;52(7):1533-1543.

8. Goldstein JL, Schrott HG, Hazzard WR, Bierman EL, Motulsky AG. Hyperlipidemia in coronary heart disease. II. Genetic analysis of lipid levels in 176 families and delineation of a new inherited disorder, combined hyperlipidemia. J Clin Invest. 1973;52(7):1544-1568.

9. Nakanura J, Shernoff DJ, Hooker CH. Good mentoring: fostering excellent practice in higher education. New York, New York, USA: JosseyBass; 2009. 